\title{
Penerapan Metode Solfegio Dalam Pembelajaran Kour
}

\author{
Emmi Simangungsong \\ Fakultas Bahasa dan Seni Universitas HKBP Nommensen, Medan \\ emmisimangunsong6|国gmail.com'
}

\begin{abstract}
Info Artikel
Diterima : 18 Agustus 2020

Revisi : 22 September 2020

Terbit : : 18 Desember 2020
\end{abstract}

\section{Key wards:}

Solfegio, Sight Singing, Ear Training.

\section{Kata Kunci:}

Solfegio, Sight Singing, Ear Training.

\section{Corresponding Author :}

Emmi Simangungsong, E-mail : emmisimangunsong6|回gmail .com

\begin{abstract}
This is a research on the application of the solfegio methad in learning chair. The aim is to analyze the relationship between the learning materials in the Solfegio course as the basic material for the Choir course. This research was conducted using descriptive qualitative research. In the Choir learning process, the lecturer using the solfegio method, which was used as a training methad to achieve an increase in vacal technique skills, with training materials specifically made for this purpose. The Solfegio method refers to singing scales, intervals and melody exercises with sillaby zolmization, namely singing musical notes using syllables. In the next development, solfegio is not only singing but also reading notation which is called sight reading and hearing the tone is called ear training. The results showed that the application of solfegio method, the sight reading and sight singing can improve students' skills in rhythms and melodies according to the tempo and frasering of the songs that studied in the Choir I, namely the song Tolite Hostias and Praise His Holy Name. The goal of this research is the student mastering the ability or skill in singing. The score of the students who get $A$ is 1 person; value A- are 14 person; the value of A/B are 4 person; the value of $B+$ are 2 person; the value of $B$ are 10 person, the value of $B$ - are 5 person. None of the students got $\mathrm{B} /$, , C+, ¿, D, and $\mathrm{E}$.
\end{abstract}

\section{Abstrak}

Penelitian ini adalah penelitian penerapan metode solfegio dalam pembelajaran Kour atau Paduan Suara. Tujuannya adalah untuk menganalisis keterkaitan materi pembelajaran mata kuliah Solfegio sebagai dasar pembelajaran mata kuliah Koгr. Penelitian ini dilakukan menggunakan penelitian kualitatif deskriptif. Dalam proses pembelajaran Koor, dosen pengampu menggunakan metode solfegic yaitu metode latihan untuk mencapai peningkatan kemampuan teknik vakal, dengan bahan latihan yang khusus dibuat untuk keperluan tersebut. Metode Solfegio mengacu pada menyanyikan tangga nada, interval dan latihan-latihan meladi dengan sillaby zolmization, yaitu menyanyikan nada musik dengan menggunakan suku kata. Dalam perkembangan selanjutnya salfegio tidak hanya menyanyikan saja tetapi juga membaca natasi yang disebut sight reading dan mendengar nada disebut ear training. Hasil penelitian menunjukkan bahwa penerapan metode sulfegio sight reading dang sight singing dapat meningkatkan keterampilan mahasiswa dalam menyanyikan ritem dan meladi sesuai tempo dan frasering lagu yang dipelajari pada mata kuliah Koor I yaitu lagu Tolite Hostias and Praise His Holy Name Target capaian dari penelitian ini adalah mahasiswa Pragram Studi Seni Musik Fakultas Bahasa dan Seni Universitas HKBP Nommensen Medan menguasai kemampuan atau skill dalam bernyanyi. Hasil nilai yang diperoleh mahasiswa yang mendapat nilai $A$ berjumlah I orang; nilai Aberjumlah 14 arang; nilai A/B berjumlah 4 arang; nilai B+ berjumlah 2 orang; nilai B berjumlah I0 orang, nilai B- berjumlah 5 orang. Mahasiswa tidak ada yang mendapat nilai B/ᄃ, ᄃ+, ¿, D, dan nilai E 


\section{PENDAHULUAN}

Dalam Kurikulum KKNI Pragram Studi Seni Musik Fakultas Bahasa dan Seni Universitas HKBP Nommensen terdapat Mata kuliah Koor dan Solfegio. Mata kuliah Solfegio ditawarkan dalam tiga (3) Semester, dengan penyebutan mata kuliah Solfegio I pada Semester I, Solfegio II pada Semester II, Salfegio III pada Semester III. Mata kuliah Kour I ditawarkan pada Semester III dan Mata Kuliah Kour II ditawarkan pada Semester IV. Penyusunan mata kuliah pada semester tersebut diatur dalam kurikulum agar mahasiswa sudah mempunyai dasar teari musik yang diajarkan dalam Solfegio I dan Solfegio II sebagai dasar untuk belajar bernyanyi dalam paduan suara/kor pada mata kuliah Kour I pada Semester III.

Tujuan mata kuliah Koor I adalah: I) Mahasiswa belajar mendalami kemahiran bernyani dalam paduan suara/koor; 2) Mahasiswa belajar bekerjasama dalam membentuk sebuah kelompok bernyanyi dalam formasi yang sempurna sesuai jenis suara masing-masing. Dalam prases pembelajaran mata kuliah Koor I, mahasiswa diajarkan teknik dasar produksi suara dan pembagian jenis suara yaitu suara sopran, alto, tenar dan bass. Pembelajaran ini penting agar mahasiswa dapat bernyanyi dengan baik dan mahasiswa dapat mengenal atau menentukan jenis suaranya masing-masing atau suara orang lain yang mau bernyanyi dalam kelompok paduan suara/kour. Dalam mempelajari suatu nyanyian/lagu paduan suara, mahasiswa harus mengetahui cara membaca ritem, melodi, dan interval nada. Sebelum mulai menyanyikan lagu paduan suara/kour, mahasiswa terlebih dulu melakukan pemanasan ( warming up): dimulai dengan latihan pernafasan, kemudian humming, baru dilanjutkan dengan olah vokal. Kendala yang dihadapi dosen pengampu pada mata kuliah Kour I adalah mahasiswa kurang mampu membidik nada, menyanyikan interval/Iompatan nada dengan tepat, membaca ritem dan melodi (hasil wawancara dengan lbu Imelda Purba, SSn, dosen pengampu mata kuliah Koar I).

Tujuan pembelajaran mata kuliah Solfegio I adalah: I) Mahasiswa belajar agar mempunyai kemampuan aural dalam teknis membaca notasi dengan bernyanyi (sight singing), latihan pendengaran (ear training) dan menulis natasi (writing) dengan penggunaan media vokal dan instrumen (alat musik); 2) Mahasiswa belajar tentang pemahaman dasar bunyi, bunyi yang teratur (nada), pemahaman dan penguasaan ritme, tangga nada, interval, akar-akar primer dan berbagai istilah musik serta nada hias dan tanda-tanda musik; 3) Mahasiwa belajar membaca dan memainkan melodi dan ritem, mendengar dan menuliskan interval nada (hasil wawancara dengan lbu Junita Batubara, SSn, MSn, PhD, dasen pengampu mata kuliah Solfegio I).

Berdasarkan tujuan pembelajaran mata kuliah Solfegio I dan mata kuliah Koor I, dapat dilihat bahwa materi pembelajaran mata kuliah Solfegio I merupakan ilmu dasar untuk belajar mata kuliah Kor I sehingga penulis tertarik meneliti lebih mendalam dengan judul "Penerapan Metade Salfegio dalam Pembelajaran Mata Kuliah Koor I pada Program Studi Seni Musik Fakultas Bahasa dan Seni Universitas HKBP Nommensen, Medan." 
Ргіег (2009:15l) menjelaskan bernyanyi memiliki teknik dasar. Teknik bernyanyi merupakan сага mempraduksi suara yang baik dan benar agar suara yang keluar dapat didengar dengan jelas, indah, dan merdu. Sikap tubuh, teknik produksi suara, warna suara dan artikulasi harus dapat dilakukan dengan benar oleh penyanyi baik secara individu maupun secara berkelompok seperti dalam paduan suara/kaor. Dalam memproduksi suara, pernafasan merupakan hal yang sangat mendasar agar penyanyi dapat menyanyikan frasa melodi dengan baik.

Menurut Sanjaya (2013: 147) metade adalah cara yang digunakan untuk mengimplementasikan rencana yang sudah disusun dalam kegiatan nyata agar tujuan yang telah disusun tercapai secara optimal. Dengan kata lain, metade digunakan untuk merealisasikan strategi yang telah ditetapkan.

Penggunaan metade Salfegiadipakai sebagai alternatif bentuk pembelajaran paduan suara/kar. Metode Solfegio adalah jenis latihan untuk mencapai peningkatan kemampuan teknik vokal, dengan bahan latihan yang khusus dibuat untuk keperluan tersebut (Syafiq, 2003: 277). Salfegin mengacu pada menyanyikan tangga nada, interval dan latihan-latihan melodi dengan sillaby zolmization, yaitu menyanyikan nada musik dengan menggunakan suku kata (Stanly, 1980: 454). Dalam perkembangan selanjutnya salfegio tidak hanya menyanyikan saja tetapi juga membaca nada yang disebut sight reading dan mendengar nada disebut ear training. Menurut Stanley Sight reading adalah membaca notasi tanpa persiapan atau kesanggupan sekaligus untuk membaca dan memainkan natasi musik yang belum pernah dikenal sebelumnya. Benward (1989: 9) menjelaskan bahwa ear trainingadalah latihan kemampuan pendengaran atau ketajaman pendengaran musik, baik ketepatan ritmik maupun ketepatan nadanya.

Selanjutnya Kodijat (1983:68) menjelaskan bahwa ear trainingadalah latihan vokal tanpa perkataan dan hanya menggunakan suku kata terbuka. Pendengaran tersebut dapat dilatih dengan cara menyelaraskan dengan not-nat yang dibaca. Semakin banyak mahasiswa berlatih akan semakin tinggi kemampuan mahasiswa dalam membayangkan nada, tepat atau tidaknya interval/lampatan nada.

Bance (2013: 75-76) menjelaskan metode kemampuan pendengaran dilaksanakan dengan menirukan berbagai kata, suku kata, terminolagi musik, syair; menirukan ritme dalam berbagai pola dengan tepuk tangan atau meja, menderapkan kaki, ucapan atau bacaan pola ritme; menirukan nada dan melodi sederhana baik peniruan vakal maupun menirukannya dengan alat musik. Metade penyampaian kemampuan membaca musik dilaksanakan dengan cara memperkenalkan ragam jenis not melalui permainan untuk menyatakan perbedaan durasi; membaca pola ritme yang dirancang dalam berbagai metrum; secara bersama-sama atau sendiri- 
sendiri; membaca natasi meladi sederhana di papan tulis atau menunjuk beberapa notasi nada dalam jangkauan C-G dengan rancangan kemudian untuk memainkannya.

Selanjutnya Banoe (2013: 76) menjelaskan metade penyampaian olah vokal dilaksanakan dengan menirukan syair dan kata-kata guna mendapatkan kesempurnaan ucapan; menyanyikan solmisasi (salfegia) dengan kesempurnaan pendengaran mutlak (al = $440 \mathrm{~Hz}$ ) dimulai dengan doremifasol bagi CDEFG, sollasidare bagi GABCD, fasallasida bagi FGABesC, remifasalla bagi DEFisGA, sebelum kelak mengenal cara membaca transpasisi dalam berbagai nada, menyanyikan lagu dalam bahasa Indanesia dengan memperhatikan persajakan dan aliterasil; menyanyikan lagu dalam bahasa Inggris atau bahasa asing lainnya di samping lagu-lagu dalam bahasa daerah Indanesia dengan lafaz yang benar. Latihan vokal dengan metode Salfegiabiasanya dilakukan secara bervariasi mulai dari mendengar selanjutnya membaca dan diakhiri dengan menyanyi dengan alat bantu. Media pembelajaran atau alat bantu yang digunakan dalam mata kuliah Koor I adalah alat musik piano.

\section{METODOLDGI PENELITIAN}

Metade yang digunakan dalam penelitian ini adalah metade kualitatif yang bersifat deskriptif, yang bertujuan agar peneliti dapat melakukan pengamatan secara mendalam dan mendapat gambaran sistematis mengenai fakta serta hubungannya terhadap objek penelitian. Lokasi penelitian dilakukan pada Program Studi Seni Musik Fakultas Bahasa dan Seni Universitas HKBP Nommensen Medan.

Pengumpulan data merupakan hal penting yang dilakukan dalam sebuah penelitian. Berbagai metade dapat digunakan dalam penelitian untuk mengumpulkan data yang dibutuhkan. Metade pengumpulan data yang digunakan dalam penelitian ini adalah wawancara, observasi, dan dokumentasi. Metode pengumpulan data tersebut dilakukan peneliti untuk memperoleh data secara holistis tentang penerapan metode salfegio dalam pembelajaran mata kuliah Koar I pada Program Studi Seni Musik Fakultas Bahasa dan Seni Universitas HKBP Nommensen, Medan.

Populasi penelitian yang diteliti adalah mahasiswa Koor I Semester Ganjil Tahun 2019/2020 sebanyak empat puluh delapan (48) arang. Peneliti tidak memilih sampel dari jumlah tersebut karena peneliti ingin mendapatkan fakta secara keseluruhan dari jumlah populasi tersebut.

Metade pembelajaran yang digunakan untuk mengimplementasikan strategi pembelajaran kocr/paduan suara adalah Metode Solfegio yaitu jenis latihan untuk mencapai peningkatan kemampuan teknik vokal, dengan bahan latihan yang khusus dibuat untuk keperluan tersebut (Syafiq, 2003: 277). Penggunaan metode Salfegiadipakai sebagai alternatif bentuk pembelajaran untuk sillaby zalmization (menyanyikan nada musik dengan menggunakan suku kata), membaca nada (sight reading) dan mendengar nada (ear training) 
(Stanly, 1980: 454). Proses pembelajaran diobservasi oleh peneliti selama satu semester (dua belas kali pertemuan di dalam kelas ditambah dua kali ujian yaitu ujian tengah semester dan ujian akhir semester). Dengan demikian hasil penelitian dapat diperoleh secara holistis. Analisis data dilakukan menggunakan analisis yang bersifat naratif-kualitatif atau dengan kata lain menguraikan atau menjelaskan secara jelas hasil temuan yang diperoleh dalam pelaksanaan tindakan yang dilakukan oleh dosen dalam kelas.

\section{HASIL DAN PEMBAHASAN}

\section{Penerapan metode Solfegio pada Mata Kuliah Koor I}

Tahapan-tahapan yang dilakukan dalam proses pembelajaran mata kuliah Koor I adalah persiapan, pelaksanaan dan evaluasi. Tahapan-tahapan tersebut dilaksanakan agar hasil yang diharapkan dapat tercapai.

Pada tahap persiapan dosen pengampu merancang Rencana Pembelajaran Semester (RPS) mata kuliah Kour I untuk T. A. 2019/2020. Materi pembelajarannya adalah mendalami kemahiran bernyanyi dalam paduan suara/kocr dan belajar bekerjasama dalam membentuk sebuah kelompok bernyanyi dalam farmasi yang sempurna sesuai jenis suara masing-masing. Dalam RPS mata kuliah Kor I, mahasiswa diajarkan teknik dasar produksi suara dan pembagian jenis suara yaitu suara sapran, alto, tenar dan bass, seperti yang ditulis dalam RPS berikut.

RENCANA PEMBELAJARAN SEMESRTER (RPS) MATA KLLIAH KODR I

\begin{tabular}{|c|c|c|c|}
\hline $\begin{array}{l}\text { Perte } \\
\text { muan }\end{array}$ & Sub kampetensi & Kriteria unit kerja & $\begin{array}{l}\text { Alokasi } \\
\text { Waktu } \\
\text { (menit) }\end{array}$ \\
\hline I & Kontrak Perkuliahan & $\begin{array}{l}\text { Penjelasan RPS dan sistem penilaian (Sikap, Quiz, UTS, } \\
\text { UAS, Keterampilan). }\end{array}$ & 100 \\
\hline$\|$ & $\begin{array}{l}\text { Pengenalan tentang } \\
\text { Koor/Paduan Suara dan } \\
\text { Teknik Bernyanyi }\end{array}$ & $\begin{array}{l}\text {-Jenis-jenis suara: Sapran, Alto, Tenor, Bass. } \\
\text {-Teknik dasar memproduksi suara: Pernafasan } \\
\text { diapragma, pemanasan (warming up), humming dan } \\
\text { olah vocal (vacalizing) }\end{array}$ & 100 \\
\hline III & $\begin{array}{l}\text { Latihan/praktek Lagu } \\
\text { "Tolite Hostias" } \\
\text { Ritem dan Melodi Frasa I } \\
\text { birama I-16 }\end{array}$ & $\begin{array}{l}\text {-Pemanasan: humming dan olah vacal. } \\
\text {-Membaca nada (sight reading) dan mendengarkan } \\
\text { nada lagu dari piano (ear training) } \\
\text {-Praktek menyanyikan Ritem dan Melodi Sopran, Alto, } \\
\text { Tenor, Bass secara berkelompak. }\end{array}$ & 100 \\
\hline
\end{tabular}




\begin{tabular}{|c|c|c|c|}
\hline IV & $\begin{array}{l}\text { Latihan/praktek Lagu } \\
\text { "Tolite Hostias" } \\
\text { Ritem dan Melodi } \\
\text { Frasa I birama I-16 } \\
\text { Frasa } 2 \text { birama 17-24 }\end{array}$ & $\begin{array}{l}\text {-Pemanasan (warming up) } \\
\text {-Membaca nada ( sight reading) dan mendengarkan } \\
\text { nada lagu dari piann (ear training) } \\
\text {-Praktek menyanyikan Ritem dan Melodi Sopran, Alto, } \\
\text { Tenor, Bass secara berkelompok. }\end{array}$ & 100 \\
\hline$V$ & $\begin{array}{l}\text { Latihan/praktek Lagu } \\
\text { "Tolite Hostias" } \\
\text { Ritem dan Meladi } \\
\text { Frasa I birama I-16 } \\
\text { Frasa } 2 \text { birama 17-24 } \\
\text { Frasa } 3 \text { birama 25-42 }\end{array}$ & $\begin{array}{l}\text {-Pemanasan (warming up) } \\
\text {-Membaca nada (sight reading) dan mendengarkan } \\
\text { nada lagu dari piann (ear training) } \\
\text {-Praktek menyanyikan Ritem dan Meladi Sopran, Alta, } \\
\text { Tenor, Bass secara berkelompok. }\end{array}$ & 100 \\
\hline $\mathrm{VI}$ & $\begin{array}{l}\text { Latihan/praktek Lagu } \\
\text { "Tolite Hostias" } \\
\text { Ritem dan Meladi } \\
\text { Frasa I birama I-16 } \\
\text { Frasa } 2 \text { birama 17-24 } \\
\text { Frasa } 3 \text { birama 25-42 } \\
\text { Frasa } 4 \text { birama 43-50 }\end{array}$ & $\begin{array}{l}\text {-Pemanasan (warming up) } \\
\text {-Membaca nada (sight reading) dan mendengarkan } \\
\text { nada lagu dari piann (ear training) } \\
\text {-Praktek menyanyikan Ritem dan Meladi Sopran, Alto, } \\
\text { Tenor, Bass secara berkelompok. }\end{array}$ & 100 \\
\hline VII & $\begin{array}{l}\text { Latihan/praktek Lagu } \\
\text { "Tolite Hostias" } \\
\text { Ritem dan Melodi Frasa 1-4 } \\
\text { birama 1-50 }\end{array}$ & $\begin{array}{l}\text {-Pemanasan (warming up) } \\
\text {-Membaca nada ( sight reading) dan mendengarkan } \\
\text { nada lagu dari piann (ear training) } \\
\text {-Praktek menyanyikan Ritem dan Melodi Sopran, Alto, } \\
\text { Tenor, Bass secara berkelompok. }\end{array}$ & 100 \\
\hline VIII & لالالAN TENGAH SEMESTER & & \\
\hline IX & $\begin{array}{l}\text { Latihan/praktek Lagu } \\
\text { "Praises Holy Name" } \\
\text { Ritem dan Melodi Frasa I } \\
\text { birama I-14 }\end{array}$ & $\begin{array}{l}\text {-Pemanasan (warming up) } \\
\text {-Membaca nada (sight reading) dan mendengarkan } \\
\text { nada lagu dari piann (ear training) } \\
\text {-Praktek menyanyikan Ritem dan Meladi Sopran Alta, } \\
\text { Tenor, Bass secara berkelompok. }\end{array}$ & 100 \\
\hline$X$ & $\begin{array}{l}\text { Latihan/praktek Lagu } \\
\text { "Praises Holy Name" } \\
\text { Ritem dan Melodi } \\
\text { Frasa I birama I-14 } \\
\text { Frasa } 2 \text { birama } 15-26\end{array}$ & $\begin{array}{l}\text {-Pemanasan (warming up) } \\
\text {-Membaca nada (sight reading) dan mendengarkan } \\
\text { nada lagu dari piann (ear training) } \\
\text {-Praktek menyanyikan Ritem dan Meladi Sopran, Alta, } \\
\text { Tenor, Bass secara berkelompok. }\end{array}$ & 100 \\
\hline
\end{tabular}




\begin{tabular}{|c|c|c|c|}
\hline XI & $\begin{array}{l}\text { Latihan/praktek Lagu } \\
\text { "Praises Holy Name" } \\
\text { Ritem dan Melodi } \\
\text { Frasa I birama 1-14 } \\
\text { Frasa } 2 \text { birama 15-26 } \\
\text { Frasa } 3 \text { birama 27-39 }\end{array}$ & $\begin{array}{l}\text {-Pemanasan (warming up) } \\
\text {-Membaca nada (sight reading) dan mendengarkan } \\
\text { nada lagu dari piann (ear training) } \\
\text {-Praktek menyanyikan Ritem dan Melodi Sopran, Alto, } \\
\text { Tenor, Bass secara berkelompok. }\end{array}$ & 100 \\
\hline$X \|$ & $\begin{array}{l}\text { Latihan/praktek Lagu } \\
\text { "Praises Holy Name" } \\
\text { Ritem dan Melodi } \\
\text { Frasa I birama I-14 } \\
\text { Frasa } 2 \text { birama 15-26 } \\
\text { Frasa } 3 \text { birama 27-39 } \\
\text { Frasa } 4 \text { birama 40-65 }\end{array}$ & $\begin{array}{l}\text {-Pemanasan (warming up) } \\
\text {-Membaca nada (sight reading) dan mendengarkan } \\
\text { nada lagu dari piann (ear training) } \\
\text {-Praktek menyanyikan Ritem dan Melodi Sopran, Alta, } \\
\text { Tenor, Bass secara berkelompok. }\end{array}$ & 100 \\
\hline$X|I|$ & $\begin{array}{l}\text { Latihan/praktek Lagu } \\
\text { "Praises Holy Name" } \\
\text { Ritem dan Meladi } \\
\text { Frasa I birama I-14 } \\
\text { Frasa } 2 \text { birama 15-26 } \\
\text { Frasa } 3 \text { birama 27-39 } \\
\text { Frasa } 4 \text { birama 40-65 } \\
\text { Frasa } 5 \text { birama 67-84 }\end{array}$ & $\begin{array}{l}\text {-Pemanasan (warming up) } \\
\text {-Membaca nada ( sight reading) dan mendengarkan } \\
\text { nada lagu dari piann (ear training) } \\
\text {-Praktek menyanyikan Ritem dan Melodi Sopran, Alto, } \\
\text { Tenor, Bass secara berkelompok. }\end{array}$ & 100 \\
\hline XIV & $\begin{array}{l}\text { Latihan/praktek Lagu } \\
\text { "Praises Holy Name" dan } \\
\text { "Tolite Hostias" }\end{array}$ & $\begin{array}{l}\text {-Pemanasan (warming up) } \\
\text {-Membaca nada (sight reading) dan mendengarkan } \\
\text { nada lagu dari piann (ear training) } \\
\text {-Praktek menyanyikan Ritem dan Meladi Sopran, Alto, } \\
\text { Tenor, Bass secara berkelompok. }\end{array}$ & 100 \\
\hline$X V$ & $\begin{array}{l}\text { Latihan/praktek Lagu } \\
\text { "Praises Holy Name" } \\
\text { dan "Tolite Hostias" }\end{array}$ & $\begin{array}{l}\text {-Pemanasan (warming up) } \\
\text {-Membaca nada (sight reading) dan mendengarkan } \\
\text { nada lagu dari piann (ear training) } \\
\text {-Praktek menyanyikan Ritem dan Meladi Sopran, Alta, } \\
\text { Tenor, Bass secara berkelompok. }\end{array}$ & 100 \\
\hline XVI & UلIAN AKHIR SEMESTER & & 100 \\
\hline
\end{tabular}

Tahap pelaksanaan/penyajian adalah penyampaian materi pelajaran sesuai dengan persiapan yang telah dilakukan agar materi pelajaran dapat dengan mudah ditangkap dan dipahami oleh mahasiswa. Menurut Sanjaya (2013: 147-1620) metode pembelajaran yang bisa digunakan untuk mengimplementasikan strategi pembelajaran adalah metade ceramah, metade demanstrasi dan metode latihan (dril). 
Ceramah merupakan komunikasi atau interaksi antara dasen dan mahasiswa. Dalam proses ceramah ini, dasen pengampu terlebih dahulu membangkitkan motivasi dan minat mahasiswa untuk belajar bernyanyi dalam paduan suara kemudian menjelaskan Rencana Pembelajaran Semester (RPS) Koar I, tentang materi pembelajaran mulai dari Pertemuan I sampai Pertemuan I6. Dosen pengampu memberikan korelasi/hubungan materi pembelajaran dengan pengalaman mahasiswa dalam bernyanyi secara umum dan secara khusus bernyanyi dalam paduan suara/kocr. Sesuai dengan RPS mata kuliah Koor I, pada Pertemuan I (pertama) dosen pengampu menjelaskan Kontrak Perkuliahan tentang RPS dan sistem penilaian (Sikap, Quiz, UTS, UAS, Keterampilan). Pada Pertemuan II, materi pembelajaran adalah pengenalan tentang Kour/Paduan Suara, jenis jenis suara: Sapran, Alta, Tenar, Bass, dan teknik dasar mempraduksi suara.

Metode demontrasi adalah metode penyajian pelajaran dengan memperagakan dan mempertunjukkan kepada mahasiswa tentang suatu proses, situasi atau benda tertentu, baik sebenarnya atau hanya sekedar tiruan. Metade latihan atau drill digunakan untuk memperaleh suatu ketangkasan atau keterampilan dari apa yang dipelajari (Sagala, 2005: 217).

Pada Pertemuan III, metode demostrasi mulai dilakukan dosen pengampu untuk pemanasan (warming up), mengajarkan teknik dasar memproduksi suara: pernafasan diafragma, humming, olah vocal (vacalizing) dan latihan/praktek Lagu "Tolite Hostias".

Dosen pengampu mengajarkan teknik memproduksi suara dengan memperagakan teknik pernafasan diafragma yang mempunyai peranan yang sangat penting untuk dapat bernyanyi dengan baik, termasuk upaya dalam memperluas wilayah suara dan artikulasi huruf vokal dan konsanan. Dosen pengampu selalu melakukan pemanasan (warming up) untuk melenturkan pita suara, mulut, tenggorakan, dan lidah. Setelah itu, humming yaitu mahasiswa melakukan dengungan sambil mengeluarkan bunyi nada dari yang paling rendah, naik setengah, dan seterusnya. Namun untuk humming tidak selalu dilakukan oleh dasen pengampu dan mahasiswa dalam setiap pertemuan. Setelah itu dilanjutkan dengan latihan membaca notasi dan praktek menyanyikan lagu dengan metade solfeggio.

Dalam metode solfeggio, mengacu pada menyanyikan tangga nada, interval dan latihan-latihan melodi dengan sillaby zolmization yaitu menyanyikan nada musik dengan menggunakan suku kata. Kemudian olah vocal dilakukan dengan menirukan syair dan kata-kata untuk mendapatkan kesempurnaan ucapan; menyanyikan solmisasi (salfegia) dimulai dengan daremifasal bagi CDEFG, sollasidare bagi GABCD, fasallasida bagi FGABesL, remifasolla bagi DEFisGA. Selain itu, olah vokal dilakukan dengan mengucapkan huruf-huruf vokal a, i, u, e, o.

Setelah proses itu dilaksanakan, dilanjutkan dengan praktek menyanyikan lagu. Dalam pembelajaran latihan/praktek menyanyikan lagu "Tolite Hostias", pertama mahasiswa langsung membaca notasi lagu tanpa 
dibantu oleh dasen pengampu untuk melihat tingkat kemampuan/keterampilan mahasiswa membaca notasi. Prosesnya pertama dilaksanakan dengan membaca ritem dan melodi frasa I lagu "Tollite Hostias" untuk suara Sopran mulai birama I-I6. Setelah itu, suara Alta birama I-IG, suara Tenar I-I6, suara Bass birama I-IG seperti notasi di bawah ini.

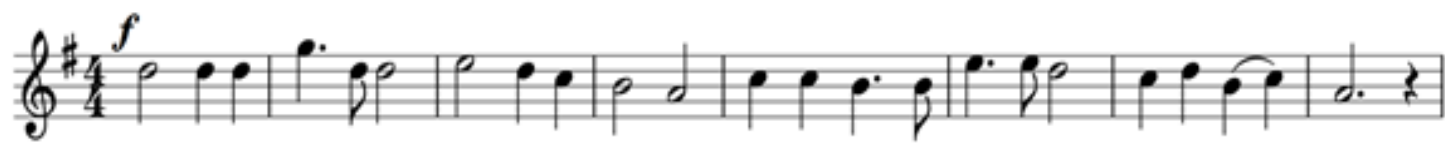

Tol-li-te hos-ti-as, et a-do-ra-te Do-mi-num in a-tri-o sancto e - jus.

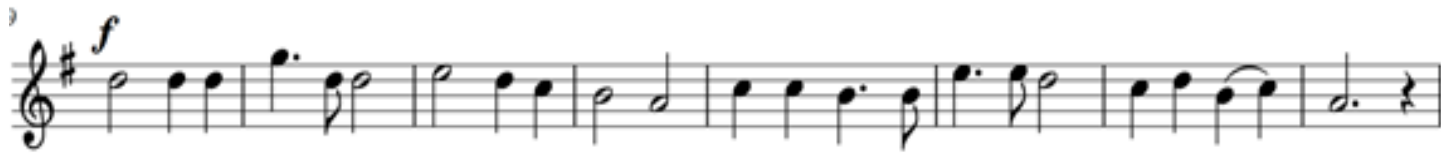

Tol-li-te hos-ti-as, et a-do-ra-te Do-mi-num in a-tri-o san-cto e - jus.

\section{Gambar 4.1 Suara Sopran birama 1-16 lagu "Tolite Hostias" (Rewrite: Penulis)}
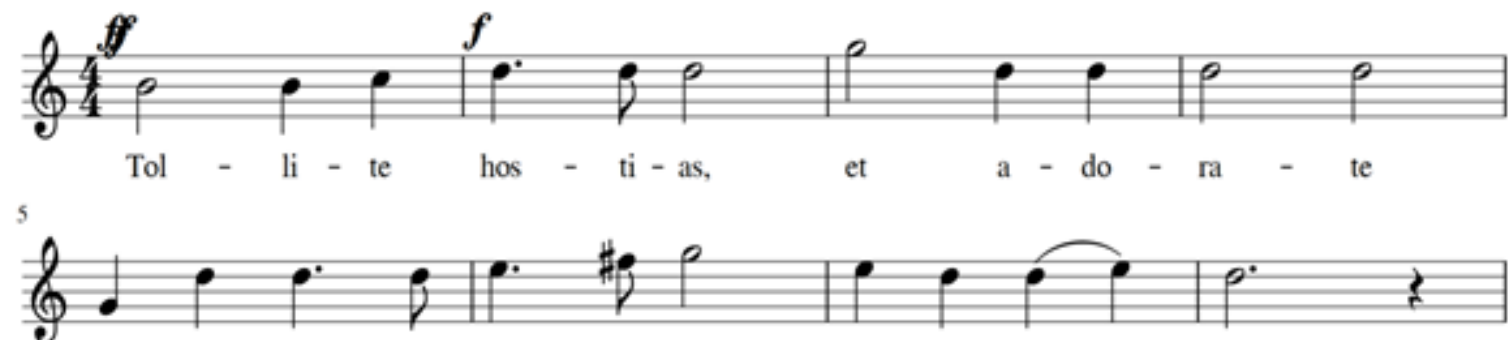
Do - mi - num
in a - tri - o
$\operatorname{san}=$ cto e $\quad-\quad$ jus.

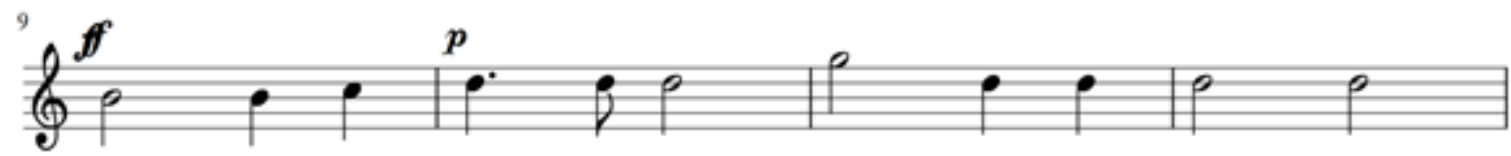

Tol - li - te hos - ti - as, et a - do - ra - te

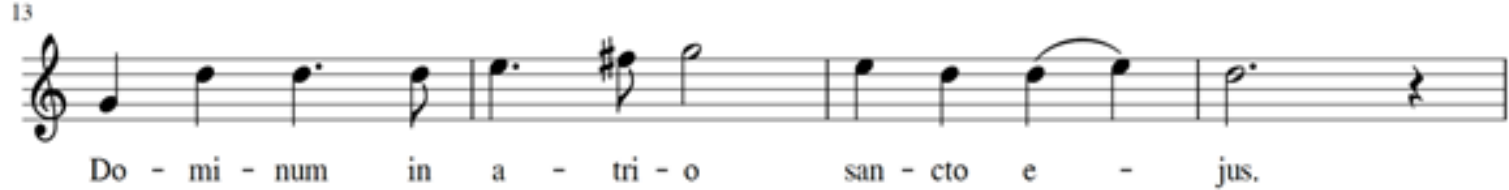

Gambar 4.2 Suara Alto birama 1-16 lagu "Tolite Hostias"

(Rewrite. Penulis) 


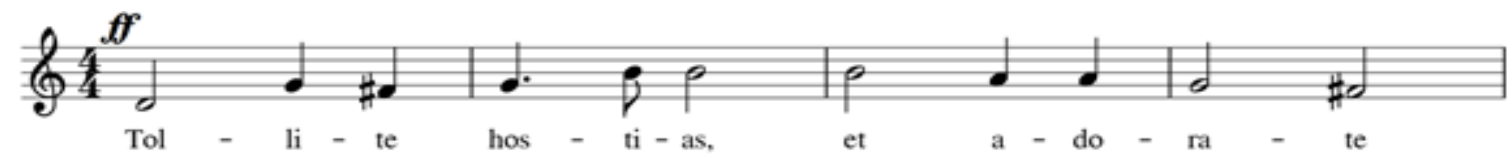

5
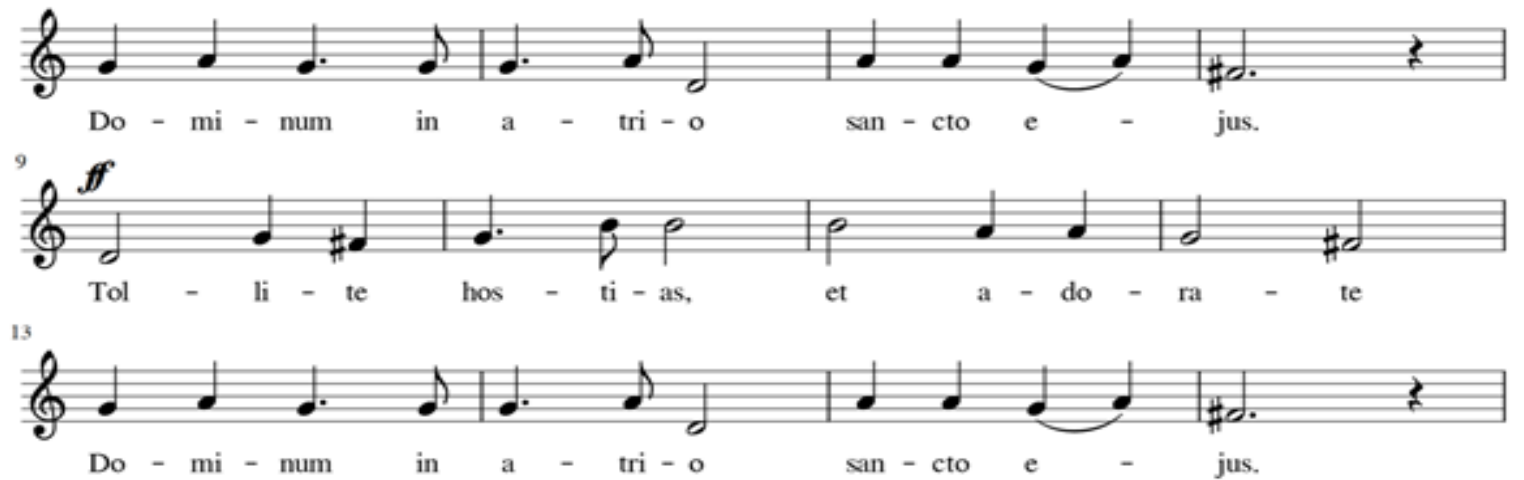

\section{Gambar 4.3 Suara Tenor birama 1-16 lagu "Tolite Hostias" \\ (Rewrite: Penulis)}
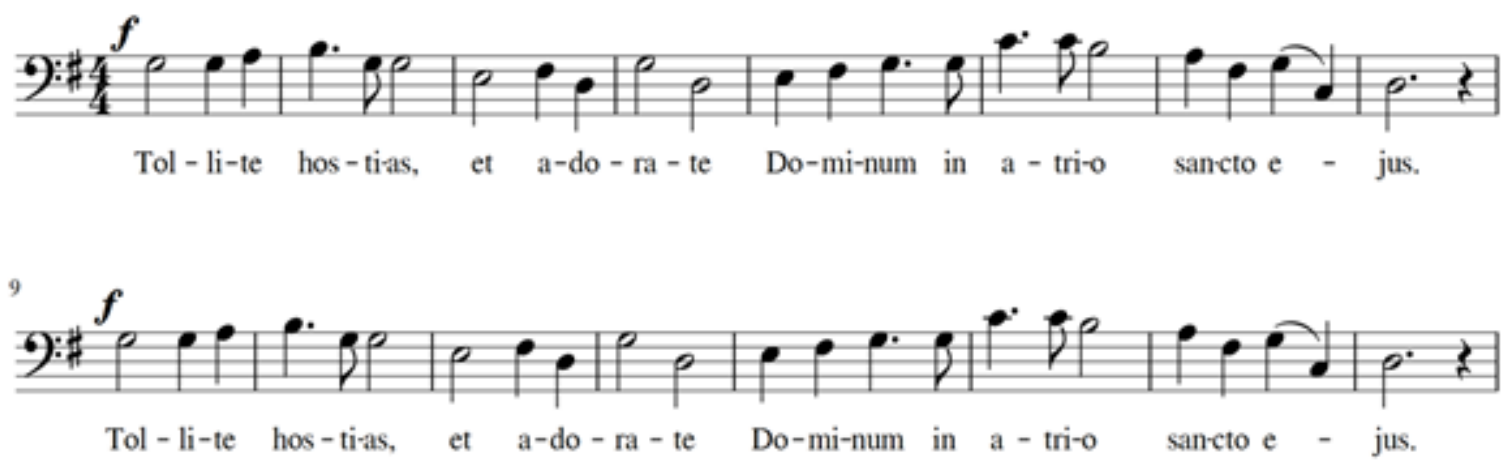

\section{Gambar 4.4 Suara Bass birama 1-16 lagu "Tolite Hostias" \\ (Rewrite: Penulis)}

Berdasarkan kondisi awal pembelajaran tersebut, hanya sebagian mahasiswa (20 arang dari populasi 48 orang) yang dapat membaca nada dan menyanyikan ritem dan melodi lagu. Melihat kondisi tersebut, dasen pengampu mendemonstrasikan membaca nada (sight reading). Sight reading dilakukan dengan cara mempelajari notasi lagu terlebih dahulu baru latihan menyanyikan teks lagu "Tolite Hostias". Dalam pembelajaran ini, yang pertama diajarkan membaca notasi lagu adalah suara Sopran, dilanjutkan dengan Suara Alta, Tenor dan Bass. Setiap suara diajarkan secara bertahap sesuai frasa lagu. Pertama suara Sopran diajarkan I6 birama, Alto I6 birama, Tenar I6 birama, Bass I6 birama (seperti Gambar 4.1, 4.1, 4.3, dan 4.4). Setelah masing-masing suara diajarkan If birama, suara Sopran, Alto, Tenor, dan Bass dilatih bernyanyi bersama. Setelah mendapat pembelajaran dengan metade sight reading terdapat peningkatan mahasiswa yang 
bisa membaca nada dan dapat menyanyikan lagu. Aktivitas individu mahasiswa lebih baik dan bersemangat, meskipun tingkat kemajuannya berbeda-beda.

Pada saat masing-masing suara Sapran, Alto, Tenor, Bass ada yang tidak pas dalam membidik nada, dosen pengampu melakukan ear training yaitu latihan kemampuan pendengaran atau ketajaman pendengaran music, baik ketepatan ritmik maupun ketepatan nadanya. Dalam proses ear training, dosen pengampu memainkan piana sambil menyanyikan lagu, dan mahasiswa mendengarkan ritem dan melodi yang dimainkan di piano sekaligus menyanyikan ritem dan melodi lagu "Tollite Hostias."

Dengan cara itu, pitch nada mahasiswa menjadi lebih tepat ketika membaca nada dan menyanyikan lagu. Melalui ear traning tersebut, semakin bertambah banyak mahasiswa yang menguasai lagu, mulanya I6 birama dan akhirnya dapat menyanyikan semua birama 1-50 sesuai masing-masing suara Sopran, Alto, Tenar, Bass.

Pada Pertemuan IV, materi pembelajarannya latihan membaca Ritem dan Melodi Frasa 2 lagu "Tollite Hostias" yaitu birama 17-24 dan mengulang Frasa I. Pada Pertemuan V, Ritem dan Meladi Frasa 3 birama $25-42$ dan mengulang Frasa I dan Frasa 2. Pada Pertemuan VI, Ritem dan Melodi Frasa 4 birama 43-50 dan mengulang Frasa I, Frasa 2 dan Frasa 3. Pada Pertemuan VII, menyanyikan Ritem dan Meladi Frasa I-4 birama 1-50 (seperti pada natasi lagu di bawah ini). Setiap pertemuan dilakukan dalam waktu 100 menit. Pada Pertemuan VIII, mahasiswa mengikuti Ujian Tengah Semester. Dengan menggunakan metode solfeggio sight reading dan ear training, sebelum ujian tengah semester mahasiswa sudah bisa bernyanyi dengan lebih harmonis walaupun belum terdengar baik dinamika lagunya. 


\section{Tollite Hostias}
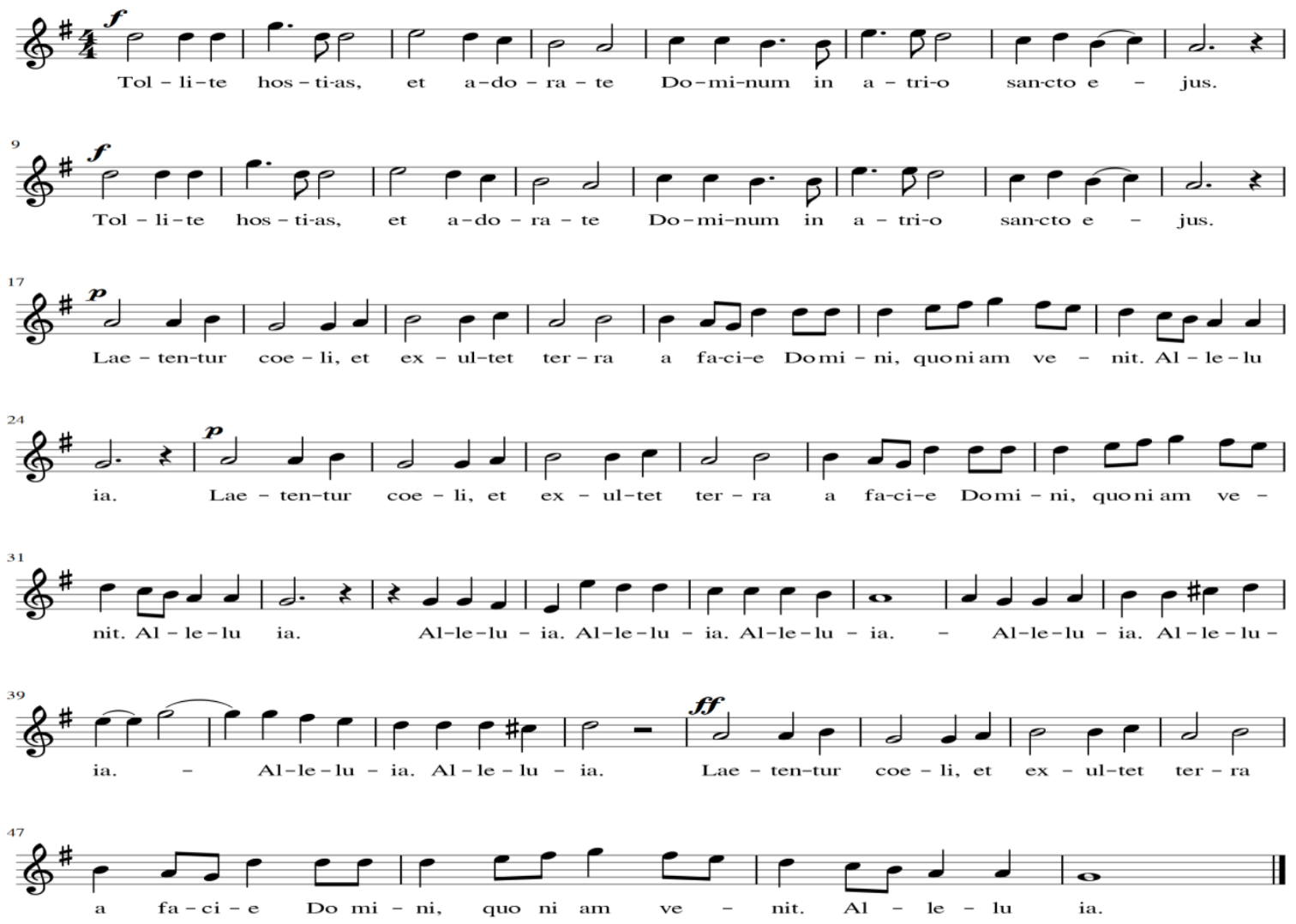

Gambar 4.5. Notasi Lagu Tollite Hostias untuk suara Sopran

(Rewrite: Penulis) 


\section{Tollite Hostias}
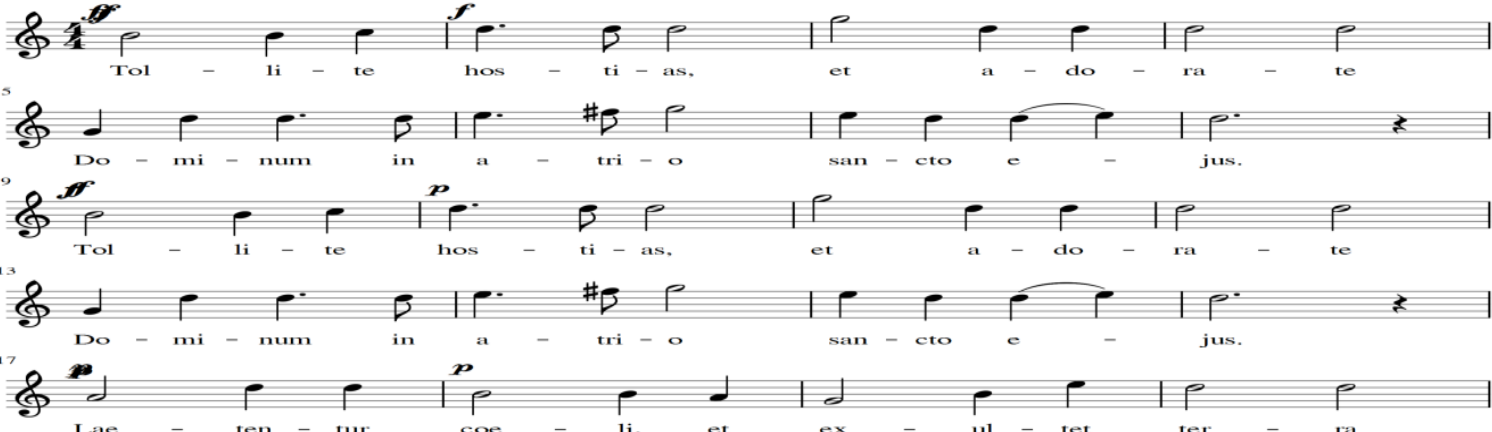

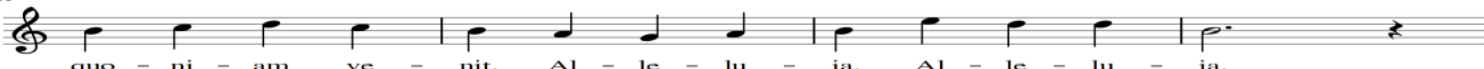

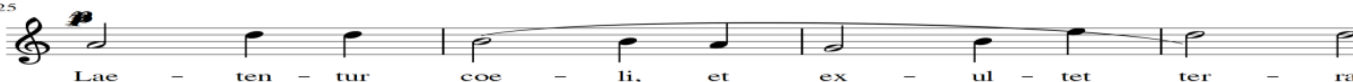

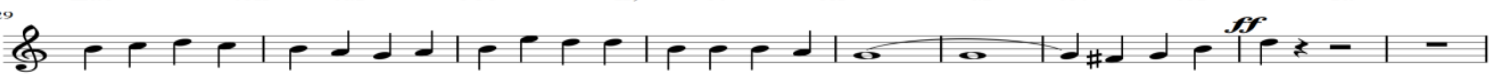

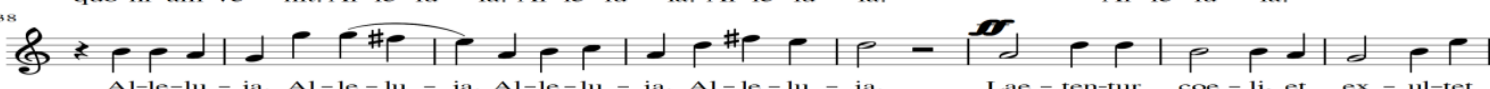

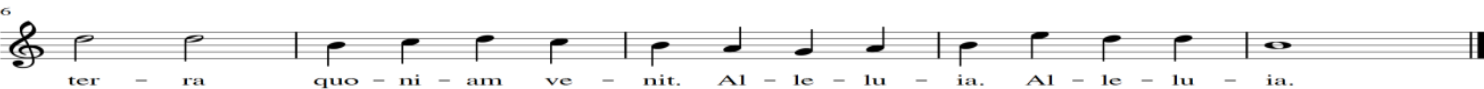

Gambar 4.6. Notasi Lagu Tollite Hostias untuk suara Alto

(Rewrite. Penulis)

Tollite Hostias

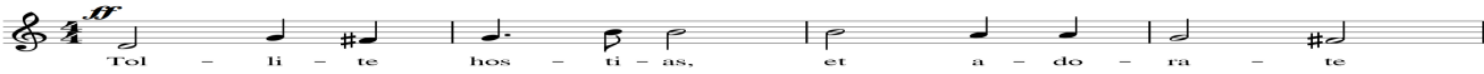

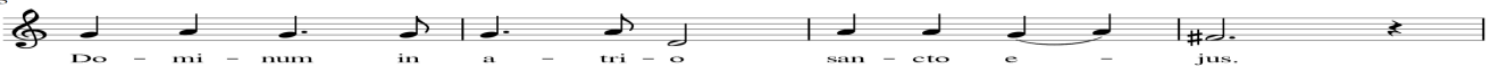

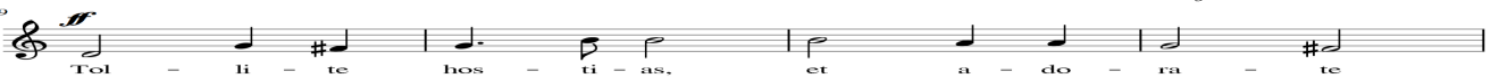

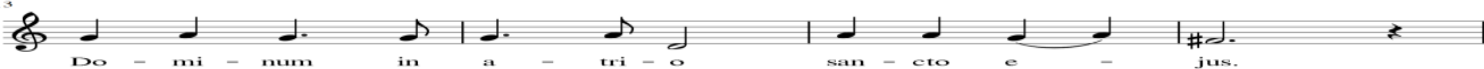

$\&$ \#

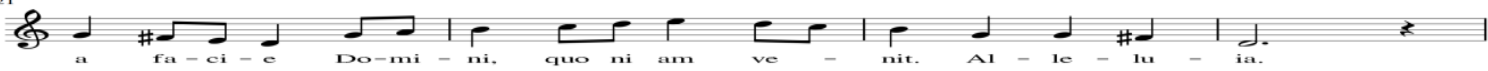

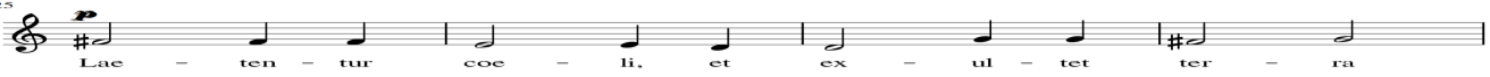

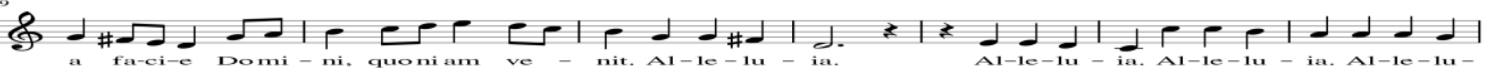

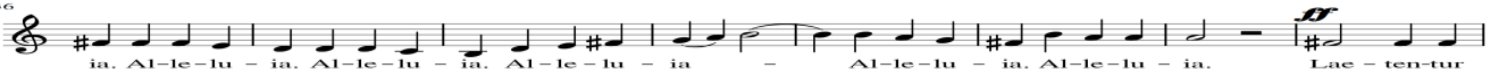

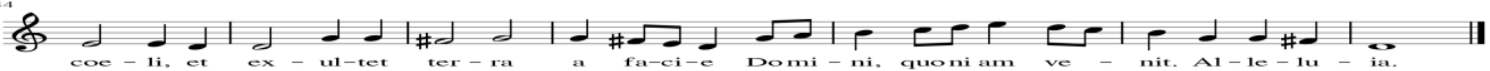

Gambar 4.7. Notasi Lagu Tollite Hostias untuk suara Tenor

(Rewrite. Penulis) 


\section{Tollite Hostias}

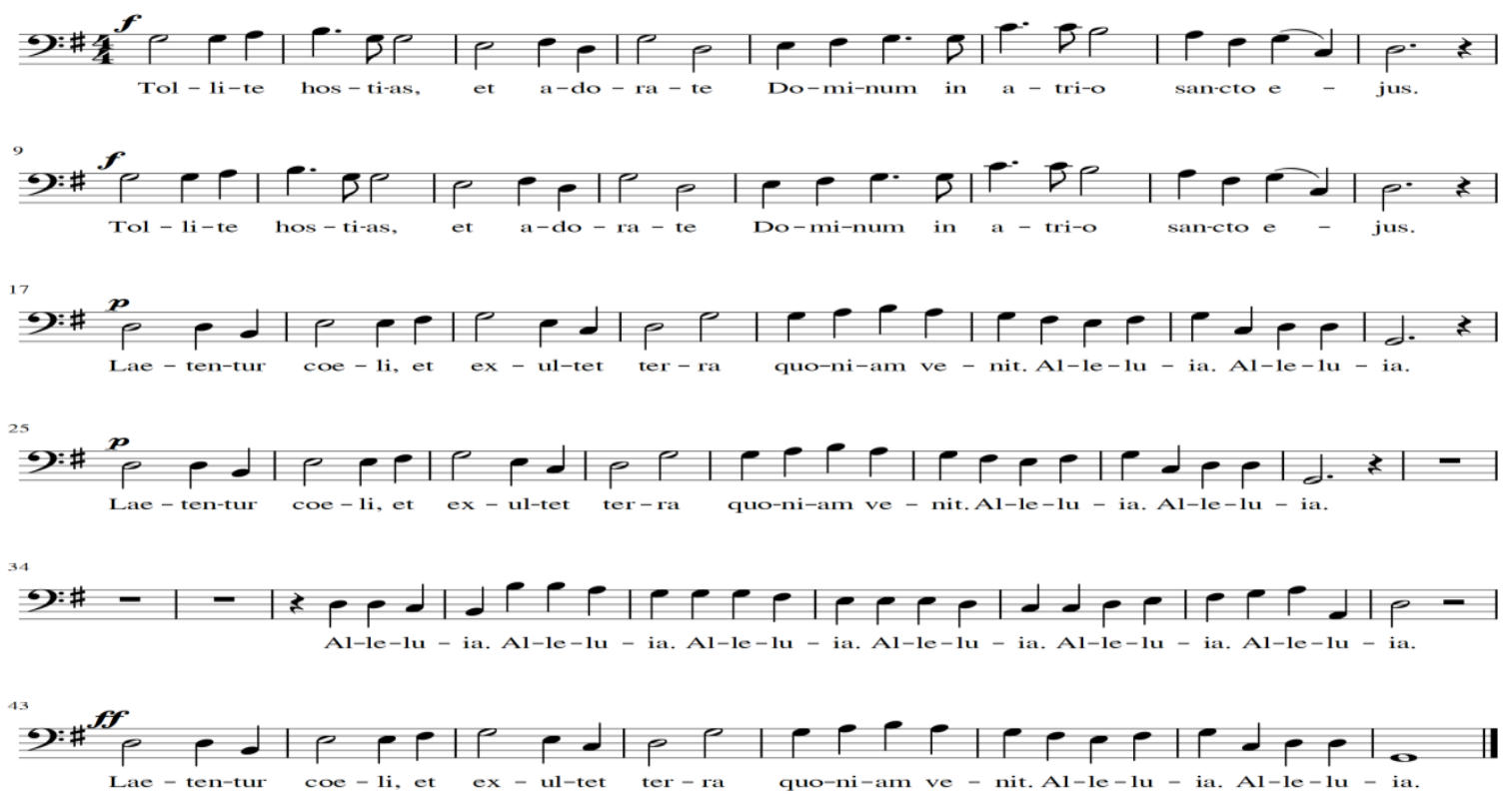

\section{Gambar 4.8. Notasi Lagu Tollite Hostias untuk suara Bass (Rewrite: Penulis)}

Setelah selesai Ujian Tengah Semester pada Pertemuan VIII, pembelajaran kemudian dilanjutkan. Pada Pertemuan IX, materi pembelajaran adalah belajar dan latihan lagu "Praise His Holy Name." Sebelum latihan membaca ritem dan melodi, mahasiswa selalu melakukan pemanasan. Metode yang digunakan dasen pengampu tetap menggunakan metode solfegio sight reading dan ear training. Pada pertemuan IX ini, mahasisswa latihan membaca Ritem dan Melodi Frasa I birama 1-14.

Pada Pertemuan X, latihan menyanyikan ritem dan melodi Frasa 2 birama 15-26 lagu "Praises Holy Name" dan mengulang Frasa I. Pada Pertemuan XI, latihan menyanyikan ritem dan meladi Frasa 3 birama 2739 dan mengulang Frasa I dan Frasa 2. Pada Pertemuan XII, latihan menyanyikan ritem dan meladi Frasa 4 birama 40-65 dan mengulang Frasa I, Frasa 2 dan Frasa 3. Pada Pertemuan XIII, menyanyikan ritem dan melodi Frasa 5 birama 67-84 dan mengulang Frasa I, Frasa 2, Frasa 3 dan Frasa 4. Pada Pertemuan XIV dan XV. mahasiswa dilatih menyanyikan Lagu "Praises Holy Name" dan "Tolite Hostias" untuk persiapan menghadapi Ujian Akhir Semester. Setiap pertemuan dilakukan dalam waktu 100 menit. 


\section{Praise His Holy Name}

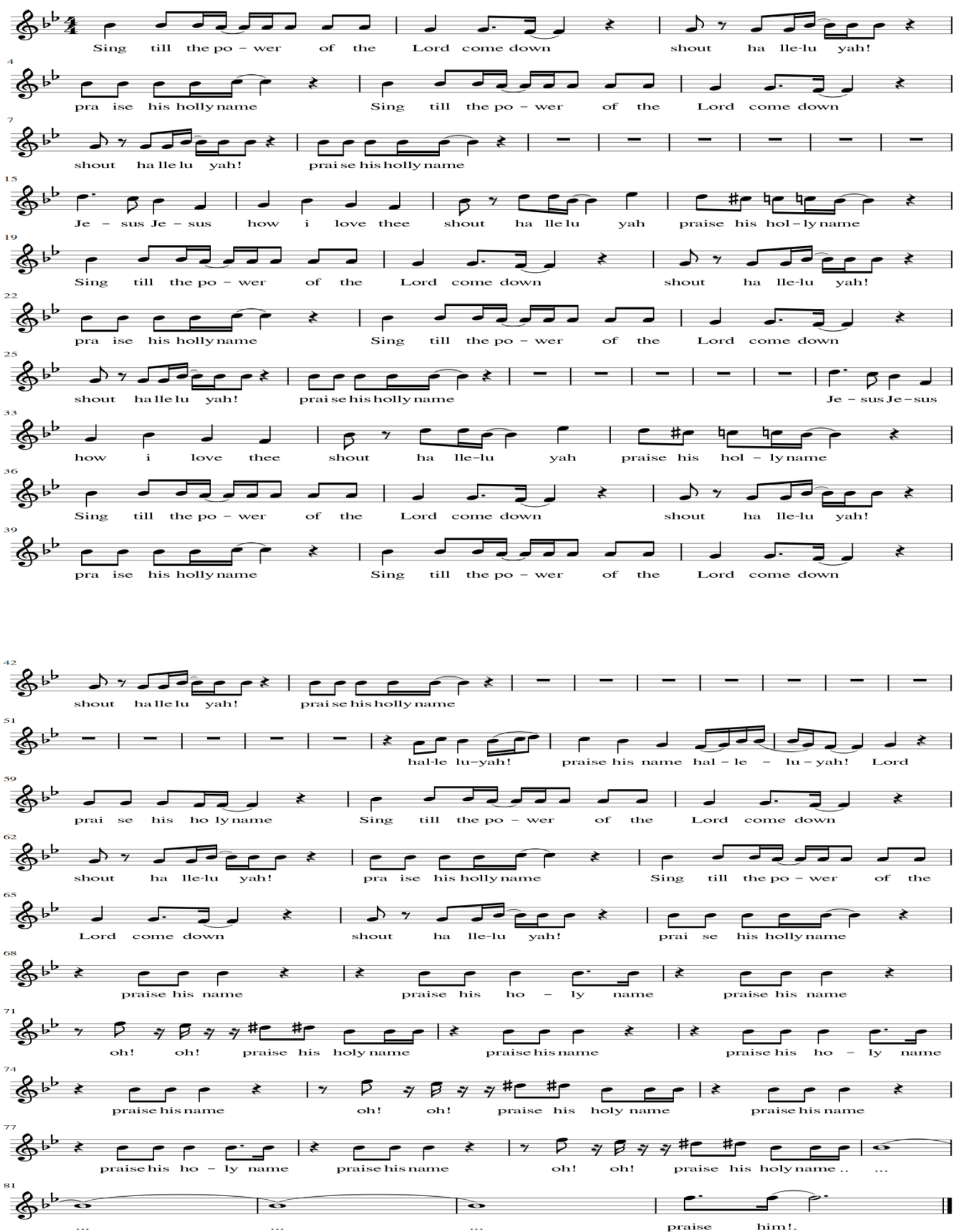

Gambar 4.9 Notasi Lagu Praise His Holy Name

(Rewrite: Penulis 
Hasil pembelajaran diperoleh melalui evaluasi untuk melihat kemajuan atau keberhasilan mahasiswa. Evaluasi dilakukan selama proses pembelajaran berlangsung, dari awal sampai dengan pelaksanaan ujian tengah semester, quiz, dan ujian akhir semester. Quiz yang dimaksud dalam pembelajaran ini adalah quiz tidak berstruktur karena pertanyaan terjadi pada saat latihan menyanyikan lagu "Tollite Hostias" dan "Praise His Holy Name" dan quiz tersebut dilakukan hanya pada saat itu.

Dalam ujian tengah semester dan ujian akhir semester, pembelajaran yang harus dicapai adalah setiap mahasiswa mempunyai keterampilan yang baik menyanyikan lagu "Tollite Hostias" dan "Praise His Holy Name." Dalam pelaksanaan ujian, mahasiswa dibagi dalam dua grup dimana masing-masing grupnya terdiri dari suara Sopran, Alto, Tenar, Bass. Dosen pengampu membagi dua grup supaya masing-masing anggata grup dapat lebih konsentrasi latihan bernyanyi karena jumlah anggata dalam setiap grup terdiri dari 24 arang.

Dalam menilai kemampuan/keterampilan mahasiswa, factor-faktor yang dinilai dasen pengampu adalah pernafasan, membidik nada dengan tepat, trampil menyanyikan setiap frasa lagu. Selain itu, dosen pengampu juga menilai sikap mahasiswa selama mengikuti pembelajaran 14 kali pertemuan yaitu disiplin, etika, kepercayaan diri, kerajinan, dan tanggung jawab. Menurut lbu Imelda Purba, SSn., nilai sikap semua mahasiswa yang mengambil mata kuliah Koor I adalah baik. Hasil nilai akhir mahasiswa diperaleh dari pembagian nilai Sikap 15\%, nilai Quiz 15\%, nilai Ujian Mid Semester 20\%, nilai Ujian Akhir Semester 20\%, dan nilai Keterampilan 30 \%. Nilai akhir mahasiswa diperoleh berdasarkan interval nilai yang sudah ditentukan oleh pihak Universitas.

Indikator ketercapaian mata kuliah Koor I adalah jika mahasiswa mampu mengatur pernafasan dengan baik ketika bernyanyi, terampil membidik nada, dan terampil menyanyikan setiap frasa lagu dengan baik dan tepat sesuai dengan tanda birama dan tempo lagu. Dengan keterampilan tersebut, hasil nilai akhir yang diperoleh mahasiswa adalah nilai A, A-, A/B. Jika mahasiswa kurang mampu mengatur pernafasan dengan baik ketika bernyanyi, kurang terampil membidik nada, dan kurang terampil menyanyikan setiap frasa lagu dengan baik dan tepat sesuai dengan tanda birama dan tempo lagu, hasil nilai akhir mahasiswa adalah nilai $\mathbf{B}+$, B, dan B-. Jika mahasiswa tidak mampu atau tidak terampil mengatur pernafasan dengan baik ketika bernyanyi, tidak terampil membidik nada, dan tidak terampil menyanyikan setiap frasa lagu dengan baik dan tepat sesuai dengan tanda birama dan tempo lagu, hasil nilai akhir mahasiswa adalah nilai C. Nilai akhir mahasiswa diperoleh berdasarkan interval nilai yang sudah ditentukan oleh pihak Universitas, sesuai Peraturan Pokok Akademik Universitas HKBP Nommensen2017 dan Penilaian Berbasis KKNI No. 143/SK/Rektor/II/2018.

Berdasarkan interval nilai dalam Peraturan tersebut, 48 arang mahasiswa yang mengikuti ujian dari Grup A dan Grup B yang mendapat nilai A berjumlah I orang; nilai A- berjumlah 14 arang; nilai A/B berjumlah 4 
orang; nilai B+ berjumlah 2 arang; nilai B berjumlah 10 arang, nilai B- berjumlah 5 arang. Mahasiswa tidak ada yang mendapat nilai B/ᄃ, 〔+, L, D, dan nilai E.

Mahasiswa yang belum memperoleh nilai akhir sebanyak 7 arang karena mahasiswa tersebut tidak hadir mengikuti ujian akhir semester. Mahasiswa yang tidak memperoleh nilai akhir sebanyak 5 arang karena kehadiran mahasiswa mengikuti perkuliahan kurang dari 75\% (<75\%) sehingga tidak diperbalehkan mengikuti ujian akhir semester.

\section{KESIMPLLAN DAN SARAN}

Berdasarkan permasalahan dan pembahasan yang dikemukakan pada bab-bab sebelumnya, penulis membuat kesimpulan bahwa metode solfegic sight reading dan ear training merupakan metode yang sesuai diterapkan dalam proses pembelajaran Koor II. Metode solfegio dapat meningkatkan keterampilan mahasiswa dalam menyanyikan ritem dan melodi pada dua lagu yang diajarkan yaitu lagu "Tollite Hostias" dan lagu "Praise His Holy Name".Hal itu dapat dibuktikan dari perolehan nilai akhir mahasiswa.

Mahasiswa yang mendapat nilai A berjumlah I arang; nilai A- berjumlah 14 arang; nilai A/B berjumlah 4 orang; nilai B+ berjumlah 2 arang; nilai B berjumlah 10 orang, nilai B- berjumlah 5 arang. Mahasiswa tidak ada yang mendapat nilai B/ᄃ, C+, ᄃ, D, dan nilai E.

Berdasarkan temuan pada hasil penelitian ini, penulis menyarankan kepada dasen pengampu sebaiknya menampilkan cuplikan video lagu yang dipelajari sehingga mahasiswa lebih termativasi untuk latihan. Kepada dosen mata kuliah yang bersifat praktek khususnya di bidang vokal, misalnya mata kuliah Instrumen Mayor Vokal dan Instrumen Mayor lainnya, dapat menerapkan metade solfegio sight reading dan ear training untuk peningkatan keterampilan mahasiswa menyanyikan lagu-lagu maupun memainkan instrumen musik.

\section{DAFTAR PUSTAKA}

Banae, Pano. 2013., Metade Ke/as Musik, Jakarta: PT Indeks.

Benward, Burt. 1989., Wark Baok in Ear Training, New Yark: Brown Campany Publisher.

Kodijat, Latifah. 1983., Istilah -/stilah Musik, Jakarta: Depdikbud.

Moleong, Lexy. 2005., Metadalagi Penelitian Kualitatif, Bandung: PT Remaja.

Prier, Karl-Edmun. 2009., "Kamus Musik", Yogyakarta: Pusat Musik Liturgi

Sagala, Syaiful. 2005., Kansep dan Makna Pembelajaran, Bandung: Alfabeta.

Sanjaya, Wina. 2013., Strategi Pembelajaran Berarientasi Standar Prases Pendidikan, Jakarta: Kencana Prenadamedia Group.

_Stanley, Wisbey, A. 1980., Music as The Saurce of Learning, Baltimare: University Park Press. 
ISSN (print) : 2722-7316

E-ISSN : :2723-1275

Syafiq, Muhammad. 2003., Ensiklapedia Musik Klasik, Yagyakarta: Adicita Karya Nusa. 